\title{
Yield Frequency Spectra and seismic design of code-compatible RC structures: an
} illustrative example

\section{Katsanos, Evangelos; Vamvatsikos, Dimitrios}

Published in:

Earthquake Engineering \& Structural Dynamics

Link to article, DOI:

10.1002/eqe.2877

Publication date:

2017

Document Version

Peer reviewed version

Link back to DTU Orbit

Citation $(A P A)$ :

Katsanos, E., \& Vamvatsikos, D. (2017). Yield Frequency Spectra and seismic design of code-compatible RC structures: an illustrative example. Earthquake Engineering \& Structural Dynamics.

https://doi.org/10.1002/eqe.2877

\section{General rights}

Copyright and moral rights for the publications made accessible in the public portal are retained by the authors and/or other copyright owners and it is a condition of accessing publications that users recognise and abide by the legal requirements associated with these rights.

- Users may download and print one copy of any publication from the public portal for the purpose of private study or research.

- You may not further distribute the material or use it for any profit-making activity or commercial gain

- You may freely distribute the URL identifying the publication in the public portal 


\title{
Yield Frequency Spectra and seismic design of code-compatible RC structures: an illustrative example
}

\author{
Evangelos I. Katsanos ${ }^{1}$ and Dimitrios Vamvatsikos ${ }^{2}$ \\ ${ }^{1}$ Department of Civil Engineering, Technical University of Denmark \\ ${ }^{2}$ School of Civil Engineering, National Technical University of Athens, Greece
}

\begin{abstract}
SUMMARY
The seismic design of an 8-story reinforced concrete space frame building is undertaken using a Yield Frequency Spectra (YFS) performance-based approach. YFS offer a visual representation of the entire range of a system's performance in terms of the mean annual frequency (MAF) of exceeding arbitrary global ductility or displacement levels versus the base shear strength. As such, the YFS framework can establish the required base shear and corresponding first-mode period to satisfy arbitrary performance objectives for any structure that may be approximated by a single-degree-of-freedom system with given yield displacement and capacity curve shape. For the 8-story case study building, deformation checking is the governing limit state. A conventional code-based design was performed using seismic intensities tied to the desired MAF for safety checking. Then, the YFS-based approach was employed to redesign the resulting structure working backwards from the desired MAF of response (rather than intensity) to estimate an appropriate value of seismic intensity for use within a typical engineering design process. For this high-seismicity and high-importance midrise building, a stiffer system with higher base shear strength was thus derived. Moreover, performance assessment via incremental dynamic analysis showed that while the code-design did not meet the required performance objective, the YFS-based redesign needed only pushover analysis results to offer a near-optimal design outcome. The rapid convergence of the method in a single design/analysis iteration emphasized its efficiency and practicability as a design aid for practical application.
\end{abstract}

KEY WORDS: performance-based seismic design; seismic code; nonlinear analysis; yield frequency spectra; reinforced concrete; multi-story space frame building.

\section{INTRODUCTION}

Performance-based earthquake engineering (PBEE) has emerged to counter the consequences observed in recent earthquakes, such as the 1994 Northridge and 1995 Great Hanshin (Kobe), aiming to mitigate their disastrous impact in terms of human casualties, monetary losses and loss of function for the civil infrastructures. Specifically, performance-based seismic design (PBSD) promotes the idea that structures should be designed to meet specific performance objectives (POs) that are tailored to the stakeholders' needs. Ideally, this would involve multiple objectives, each one comprising a structural response, damage or loss threshold together with a maximum allowable MAF of exceedance. Typically, the POs are defined at increasing levels of seismic intensity (i.e., lower MAFs), allowing for a detailed definition of the desired structural performance for both frequent and rarer earthquake ground motions. Such fundamental notions of PBSD were elaborated in SEAOC's Vision 2000 report [1] 
while, afterwards, were incorporated in several mainstream documents such as FEMA-273 [2] for the rehabilitation of existing buildings, FEMA-302 [3] for the design of new buildings and lately ASCE/SEI 07/10 [4]. Still, such approaches lacked a rigorous probabilistic basis until the emergence of the Cornell-Krawinkler framework [5], adopted by the Pacific Earthquake Engineering Research (PEER) Center. The latter provided a fertile platform for assessing losses, casualties and downtime, which was gradually expanded to be used for design (rather than just for assessment purposes) of buildings and bridges (e.g., [6-8]).

Despite the advancements already achieved in PBSD, progress regarding the development of a practicable design process has been slow. This is mainly attributed to the fact that structural design is an inverse problem and, in case of the earthquake loading, it is based on the non-invertible nonlinear relationships between seismic intensity and structural demand. Thus, iterations are necessary, severely increasing the computational burden as each cycle involves a sequence of re-design and re-analysis, where the latter is a performance-based assessment employing nonlinear static or dynamic analysis procedures. To mitigate the adverse effects of iterations, several researchers introduced numerical optimization techniques in order to hasten converge (e.g., [7-10]). The aforementioned methods offer considerable gains in efficiency, yet their implementation is beyond the means of most design offices.

On the other hand, code-based procedures for seismic design are undeniably practical, yet they cannot be considered to be performance-based in the true sense. To be more specific, they may incorporate the MAF of exceeding certain seismic intensity levels (e.g. the typical $10 \%$ in 50yrs for Life Safety), yet they do not propagate such probabilistic input to the output response, essentially neglecting the effect of response variability. Similarly, they lack a treatment for all the sources of uncertainty inherently related to the structural analysis and design/assessment process. The result of such methods is not as reliable as needed for PBSD, since only evidence is provided, but no proof, that the performance targets have been successfully met. To mitigate the undesirable consequences of such approaches to seismic safety, conservative values are typically employed for the behavior or strength reduction factors used to reduce the seismic forces applied to a linear structure in approximation of the effects of nonlinear behavior. The end result is a design that sits within a grey zone, where meeting the stated objectives is not guaranteed. Displacement-based design procedures (e.g., [11-15]) are not immune to this criticism; they may provide a more rational approach to determining a satisfactory structural configuration and associated member sizes, however they still tie performance to the input intensity rather than the output response. For a more detailed discussion of different approaches to seismic design see Vamvatsikos et al. [16].

In an attempt to reconcile the virtues of PBSD with the simplicity of code approaches, Vamvatsikos and Aschheim [17] introduced the so called "Yield Frequency Spectra". This novel framework offers a robust means to determine the minimum strength required for a preliminary design that provides a desired level of confidence in satisfying multiple POs within the framework of the PBSD of the structural system studied. Along these lines, the objectives of the study presented herein are to:

(a) illustrate the YFS framework through its application for the PBSD of an 8-story reinforced concrete (RC), space frame structure, subjected to the POs implied by the Eurocode;

(b) identify the critical points of applying YFS, providing, at the same time, a smooth transition from the code-based design to the proposed method;

(c) evaluate the efficiency and practicability of YFS as an alternative aid for structural design that materializes the basic principles of PBEE. 


\section{YFS FRAMEWORK: DEFINITION AND CONCEPTUAL CONSIDERATIONS}

Yield Frequency Spectra (YFS) constitute a visual representation of a structural system's performance that associates the MAF of exceeding any displacement $\delta$ (or ductility $\mu$ ) value with the system yield strength $V_{y}$ (or yield strength coefficient, $C_{y}=V_{y} / W$, where $W$ is the seismic weight). The calculation of YFS is dependent on a constant system yield displacement, $\delta_{y}$. Thus, variations in strength $\left(C_{y}\right)$, presented on a YFS plot, are related to changes in both vibration period and stiffness. For an elastic-perfectly-plastic oscillator, an example YFS plot is presented by Fig. 1, where three POs are specified (by the " $x$ " symbols) and curves representing the site hazard convolved with structural system's fragility are plotted for fixed values of $C_{y}$. The minimum acceptable $C_{y}$ that fulfills the specified POs can be readily determined and constitutes the strength to be used as a starting point for the PBSD of the structural system studied.

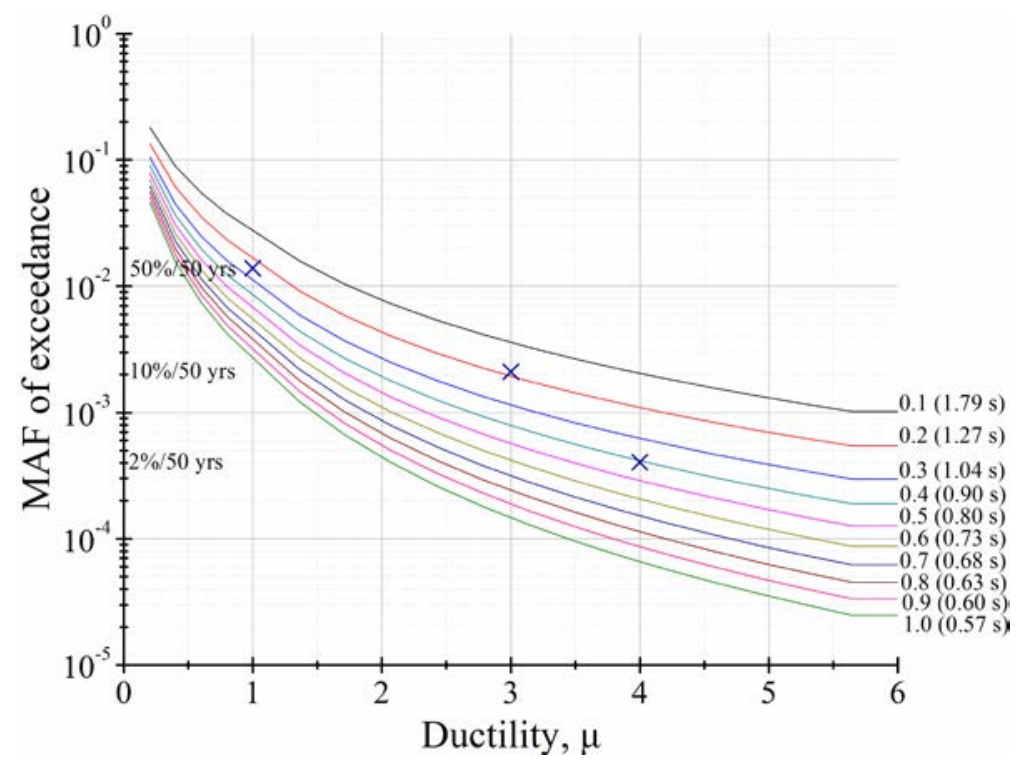

Figure 1. YFS contours at $C_{y}=0.10, \ldots, 1.0$ determined for an elastoplastic system $\left(\delta_{y}=0.08 \mathrm{~m}\right)$ for a Californian site. The " $x$ " symbols indicate three performance objectives, $\mu=1,3,4$ at $50 \%, 10 \%$ and $2 \%$ in 50 yrs exceedance rates, respectively. The third objective governs with $C_{y} \approx 0.408$ and the corresponding period is $T=0.888 \mathrm{~s}$.

The formulation of the YFS-based design process is founded on the stability of a system's yield displacement, $\delta_{y}$. For a given structural configuration, Priestley [13] and Aschheim [15] have already identified the near-insensitivity of $\delta_{y}$ to changes in the system's strength and stiffness compared to the less stable fundamental period, $T$, typically employed in code approaches. Thus, a good estimate of the system's $\delta_{y}$ is possible using structural properties that are a priori known to the designer, considerably reducing the number of design/analysis cycles $[13,15]$. Furthermore, the equivalent single degree of freedom system (ESDOF) approximation is adopted similarly to all modern design codes as the basis for approximating the inelastic behavior of the building. Finally, a fully probabilistic basis for the design is employed based on a reduced version of the Cornell-Krawinkler framework [5] to incorporate and propagate all sources of uncertainty (both aleatory and epistemic) related to the seismic hazard, structural modeling and analysis framework and thus, achieve the desired level of confidence in the design results.

The essential ingredients to calculate the YFS based on either a numerical or an analytical 
approach [17] are: (a) the site-specific seismic hazard surface for spectral acceleration at a range of periods, (b) an estimate of the yield displacement, $\delta_{y}$, of the structural system, (c) its damping ratio and the shape of its force-deformation backbone (e.g., elastic, elastoplastic etc.), (d) the set of POs to be met by the design, expressed in terms of the allowable MAFs of exceeding specific global ductility or displacement limits and (e) an estimate for the magnitude of the additional uncertainties (i.e. epistemic dispersion, $\beta_{U}$ ), beyond the record-torecord variability, that encumber the distribution of the response given seismic intensity and the ductility capacity related to the POs. After defining the aforementioned parameters, displacement (or ductility) hazard curves $\lambda(\delta)$ provide a unique representation of the system's probabilistic response [18]:

$$
\lambda(\delta)=\int_{0}^{+\infty} F\left(S_{a c}(\delta) \mid s\right)|\mathrm{d} H(s)|
$$

where $\lambda(\cdot)$ is the MAF of exceeding the displacement demand, $\delta$, and $S_{a c}(\delta)$ is the random limit state capacity, representing the minimum intensity level for a ground motion record to cause a displacement $\delta$ to be exceeded. $F(\cdot)$ is the cumulative distribution function of $S_{a c}$ (typically lognormal) evaluated at a spectral acceleration value of $s$ while $H(s)$ is the associated hazard rate, or MAF of exceeding $s$. Epistemic uncertainty is typically introduced via the first order assumption, i.e., by assuming that it only induces additional dispersion, $\beta_{U}$, to the random limit state capacity, $S_{a c}(\delta)$, without changing its median $[18,19]$.

The main outcome of the YFS framework is the structure's strength, normalized as $C_{y}$, that is required for the imposed performance levels to be satisfied. Due to the assumption of a constant $\delta_{y}, C_{y}$ essentially becomes a direct replacement of the period $T$ :

$$
T=2 \pi \sqrt{\frac{\delta_{y}}{C_{y} g}} \text { or } C_{y}=\frac{\delta_{y}}{g}\left(\frac{2 \pi}{\mathrm{T}}\right)^{2}
$$

The origin, the definition as well as the calculation of the YFS are described in depth elsewhere [17].

\section{APPLICATION OF THE YFS FRAMEWORK FOR THE CASE STUDY BUILDING}

\subsection{Design according to the Eurocodes}

To illustrate the application of the proposed YFS framework for the PBSD of structures, an 8story RC space frame building is studied, roughly based on the configurations analyzed by Haselton [20]. The overall plan dimensions are $18.30 \mathrm{~m}$ x $18.30 \mathrm{~m}$ while the total height, $H_{\text {tot }}$, is $32.60 \mathrm{~m}$, with story heights of $4.0 \mathrm{~m}$ for all stories except the first that is $4.6 \mathrm{~m}$ high (Fig. 2). Each of the $3 \times 3$ slabs that comprise each floor is a two-way ribbed slab incorporating hollow blocks to reduce weight. Besides the dead loads from the self-weight of the structural members, an additional permanent load of $1.50 \mathrm{kN} / \mathrm{m}^{2}$ is considered for floor finishes, together with a $1.20 \mathrm{kN} / \mathrm{m}^{2}$ (times the story height) load along each beam line due to light ductile partitions and external facades. The live load is $2.0 \mathrm{kN} / \mathrm{m}^{2}$. All loads are chosen to be in agreement with Eurocode provisions.

The benchmark building was initially designed and detailed according to Eurocodes provisions (EN1990 [21], EN1992-1 [22], EN1998-1 [23]). A 3D analysis model was created for the structural design realization using commercial structural analysis software. Seismic 
loads, being consistent with the highest importance factor $\left(\gamma_{I}=1.4\right)$ imposed by EN1998-1 [23] and a reference peak ground acceleration, $a_{g R}$, of $0.36 \mathrm{~g}$, were accounted for the modal response spectrum analysis (MRSA) of the building, assumed to be founded on firm soil conditions (i.e., Soil Type B according to EN1998-1 site classification). Moreover, Ductility Class High (DCH) is considered. The behavior factor, $q$, was set equal to 5.85 , indicative of the multi-story and multi-bay, high ductile frame system while no further reduction was calculated for the $q$-factor since the specific building is classified as regular in elevation based on the four qualitative criteria prescribed by EN1998-1. The taller first story only induces an approximate $25 \%$ stiffness reduction vis-à-vis higher ones, a value lower than the maximum value of $30 \%$ mandated by ISE [24] for regularity. Similarly, the strength of any story is approximately higher than $80 \%$ of that of the story above, fulfilling in such a way the relevant criterion described by ISE [24].
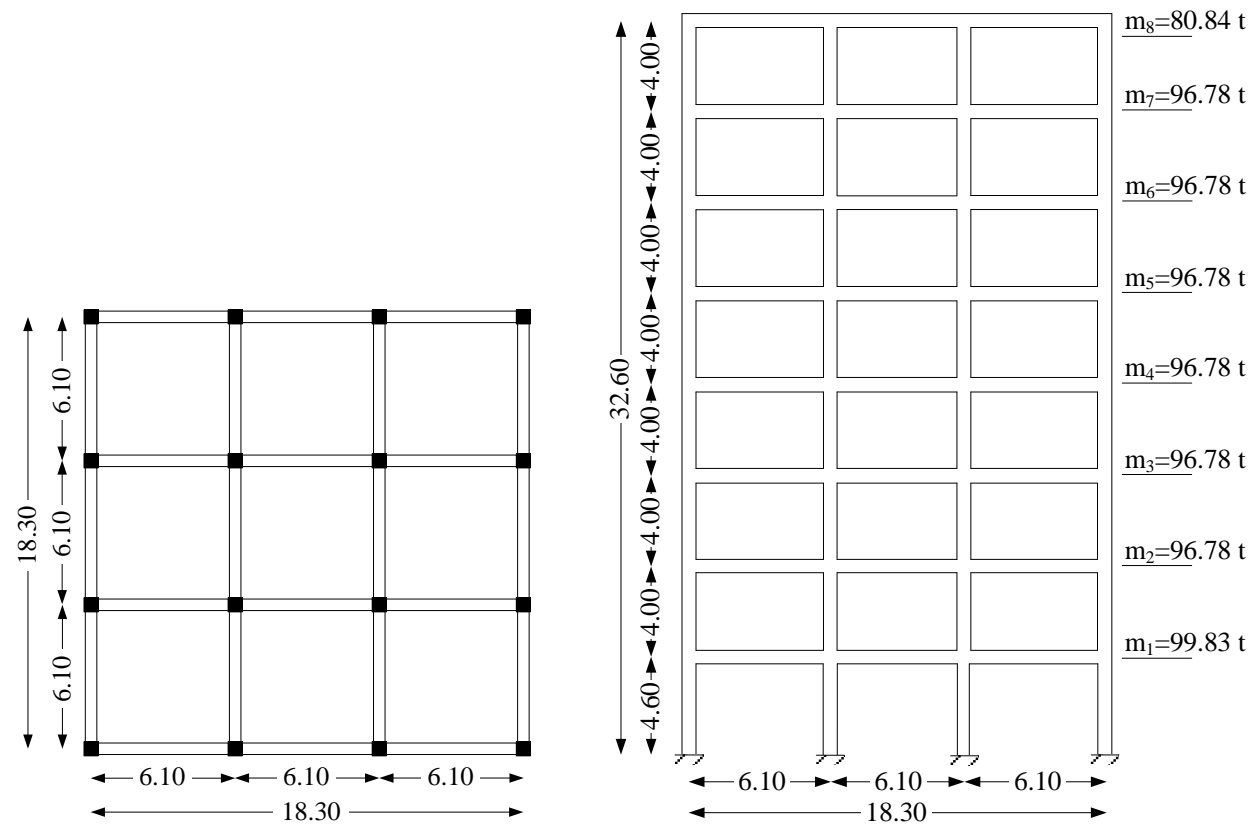

Figure 2. Plan view of a typical story (left) and internal frame (right) of the 8-story RC building studied herein.

The selection of such a highly demanding structural realization (i.e., increased seismic loads along with the consideration of $\mathrm{DCH}$ ) was motivated in order to validate the currently proposed YFS framework for a high performance, yet still code compatible, design case allowing us to compare and identify potential limitations that may emerge vis-à-vis the wellknown code approach. Regarding the material properties used herein, a characteristic cylinder strength of $35 \mathrm{MPa}$ was considered for concrete (i.e., concrete class C35/45) while Tempcore steel of grade S500 (Class C) with characteristic yield strength equal to $f_{y k}=500 \mathrm{MPa}$ was adopted for both the longitudinal and transverse reinforcing bars. To account for the effect of concrete cracking, the elastic flexural and shear stiffness properties of the $\mathrm{RC}$ members were taken, for the structural analysis, equal to one-half of the corresponding stiffness properties of the uncracked elements [23]. However, this rather simplified practice, adopted by EN1998-1 most probably based on designers' convenience criteria, disregards the varying level of cracking expected for different RC structural members during the earthquake-imposed cyclic inelastic deformation (e.g., columns carrying large axial forces are prone to lower cracking compared to members under almost pure flexure) [25]. Moreover, based on the XC3 exposure 
class (i.e., corrosion induced by carbonation under moderate humidity carbonation [22]), the nominal concrete cover was equal to $0.03 \mathrm{~m}$ for the slabs and $0.035 \mathrm{~m}$ for beams and columns. Square cross-sections of $0.60 \mathrm{~m} \times 0.60 \mathrm{~m}$ were adopted for the columns while the beams were designed with depth and width of $0.60 \mathrm{~m}$ and $0.40 \mathrm{~m}$, respectively.

The design of the case study building was primarily controlled by Eurocodes-imposed drift limitations (i.e., dominance of the Damage Limitation, DL, performance objective) and hence, the associated increased stiffness requirements dictated the use of such large enough crosssections for the structural members. On the other hand, the strong column-weak beam requirement, enforced through rigorous standards on member detailing requirements, and the joint shear capacity provisions were found of secondary importance for the case at hand. Based on EN1998-1 the seismic design values of response quantities (e.g., displacements, axial and shear forces, bending moments) at each story were increased by the corresponding factor of $1 /(1-\theta)$, since the interstory drift sensitivity coefficient, $\theta$, varies between 0.10 and 0.20 for the lower five stories, indicating the sensitivity of this pure frame system to $P-\triangle$ effects:

$$
\theta=\frac{P_{\text {tot }} \cdot d_{r}}{V_{\text {tot }} \cdot h}
$$

where $P_{\text {tot }}$ is the total gravity load at and above each story considered, $d_{r}$ is the design interstory drift, $V_{\text {tot }}$ is the total seismic story shear and $h$ is the interstory height. It is noted that the maximum interstory drift, amplified by $1 /(1-\theta)$, was estimated for the second story to be equal to $0.66 \%$, lower than $0.75 \%$, which is the allowable drift, $\theta_{I D R}^{\lim , D L}$, associated with the Eurocodes-imposed DL requirement in case of buildings with ductile non-structural members.

Regarding the cross-sections' detailing, the reinforcement ratios for the vast majority of columns and beams were found to be close to the code-prescribed minimum reinforcement. Particularly, the longitudinal reinforcement ratio calculated for most of the columns, was slightly higher than $10 \%$ o while the columns of the second story, where the highest interstory drift was calculated, were designed with $\rho=14 \%$. Longitudinal reinforcement ratios equal to $16 \%$ were calculated for the columns of the seventh story, attributed to the higher modes that amplify locally the dynamic response. Additionally, the longitudinal (tensile) reinforcement ratio, calculated for both the supports and the middle span of beams, varied between 3.5\% and $9.50 \%$, slightly higher than the Eurocodes-imposed minimum requirement of $3.2 \%$. In terms of the transverse reinforcement, stirrups for structural members were mainly controlled by shear capacity design and confinement requirements, the latter being valid for the columns.

\subsection{Performance assessment of the initial design}

Earlier discussion addressed the issues of the code framework for the seismic design of a structure and the involved uncertainty (from several assumptions and approximations made) related to the degree of confidence of having achieved the stated objective(s). To be more specific, driven mainly by simplicity reasons, seismic code provisions introduce two main assumptions: (a) the use of the behavior factor, $q$ (or strength reduction factor, $R$, based on US guidelines), to consider the effect of yielding and ductility and (b) the neglect of the effect that uncertainty introduces both in demand and capacity. As identified by Cornell et al. [19], the uncertainty in demand, given the seismic intensity, essentially means that in order to determine compliance vis-à-vis a given PO, a range of intensity levels needs to be considered rather than just the one that corresponds to the MAF defining the performance objective. 
Otherwise, the shape of the hazard curve and the long right tail of the lognormal distribution of demand given intensity ensure that unconservativeness will creep into any design or assessment approach. At the same time, it is highly unclear if this unconservativeness can be mitigated by the conservative behavior (or strength reduction) factors along with the safety factors applied to materials properties and loading conditions. Given these considerations, it is important to assess in a rigorous way if the code-based design fulfills the performance-based criteria imposed by the Eurocodes themselves, assuming they are applied at the response output rather than the intensity input. In other words, we shall check whether the actual MAF of the response is lower (i.e. safe) compared to the target PO (i.e., the associated maximum allowable MAF of exceedance) when the code design is satisfied.

A two-dimensional (2D) model for the internal frame of the double-symmetric building (Fig. 2) was used to assess the seismic response via incremental dynamic analysis (IDA) [26]. Although a 2D model incorporating one interior and one exterior frame side-by-side would offer higher fidelity, this would be the case only for higher ductility. Modeling only the interior frame offers equal accuracy in the near-yield range (which is of interest) and similar or slightly conservative results near collapse (see also in [20]). The model was created with Opensees [27] using forced-based distributed plasticity fiber elements for beams and columns. The exact detailing for all the structural members, derived by the initial, code-based design of the case study building, was used to provide further refinement in cross-sections modeling. A uniaxial nonlinear model, proposed by Popovics [28], was employed for concrete and the confinement-related parameters were calculated on the basis of the model introduced by Mander et al. [29]. Moreover, steel reinforcing bars were modeled using a uniaxial bilinear constitutive law accounting for pinching and stiffness degradation. Since the initial, codecompatible design of the 8-story building was to be assessed, mean values for materials properties were adopted for this purpose: the mean yield strength for the reinforcing steel was taken equal to $f_{y m}=1.15 \cdot f_{y k}=575 \mathrm{MPa}$ and the mean concrete compressive strength was $f_{c m}=f_{c k}+8=43 \mathrm{MPa}$. Finally, the eigenvalue analysis of the model showed that the first three (uncracked stiffness) modes vibrate at $T_{1}=1.233 \mathrm{~s}, T_{2}=0.403 \mathrm{~s}$ and $T_{3}=0.235 \mathrm{~s}$.

Due to considerable record-to-record variability, IDA requires a large enough set of records to achieve reliable results. This natural variability is an essential component of seismic assessment that should not be artificially suppressed by selecting motions based on their matching with a target design or uniform hazard spectrum [30]. Typically, 30 to 40 ground motions are deemed adequate to assess the mean and dispersion of practically any response quantity (engineering demand parameter, EDP). Nevertheless, Eads et al. [31] have shown that significantly scattered MAF estimates can still be found unless an even larger record suite is employed. To avoid any such bias, the 2D frame model was subjected to 300 strong ground motions obtained from the PEER NGA Database [32], with a wealth of different characteristics in terms of seismological parameters (earthquake magnitude, sourceto-site distance and rupture mechanism), amplitude and frequency content as well as soil conditions, in which the motions were recorded. A comprehensive description of the selected earthquake records can be found elsewhere [33].

The damped ( $\zeta=5 \%$ ) spectral acceleration at the structure's effective, first-mode period, $S_{a}\left(T_{e f f}, 5 \%\right)$, was adopted herein as the intensity measure (IM) for IDA. The effective period,

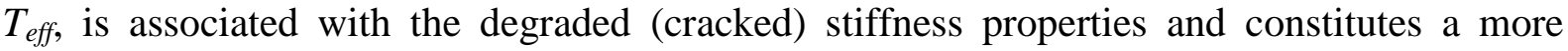
reliable approximation of the structural period than the initial, purely elastic (uncracked) period, $T_{e l}$. Moreover, spectral acceleration ordinates at an elongated period (i.e., $T_{e f f}$ ) have been found to be more efficient and sufficient vis-à-vis ordinates at the initial period (i.e., $T_{e l}$ ), 
especially when significant loss of stiffness has occurred [34]. This is the case here due to considerable cracking of the initially unstressed fiber sections. Still, the spectral acceleration at any single period may not be fully sufficient IM for any MDOF structure subjected to high levels of inelastic deformation [35]. Nevertheless, this is not the case here, as the DL checking governs. Thus, any MAF assessment will be performed within the (nominally) pre-yield, elastic region, where only low scaling factors are needed and spectral shape is not a significant issue. To further improve precision when estimating drifts for DL checking, the value of $T_{\text {eff }}$ was chosen to correspond to the point where the structure attains the corresponding EN1998-1 limiting interstory drift ratio, $\theta_{I D R}^{\lim , D L}=0.75 \%$, for ductile partitions.

To establish this point, a first-mode pushover analysis was employed as shown in Fig. 3 (left). Therein, the significant effect of cracking is apparent, captured by the use of fiber elements and motivating our choice of $T_{\text {eff. }}$ At the same time, fiber elements may limit the model's ability to capture the near-collapse behavior [20]. As we are only interested in the dominant near-yield behavior of this flexible structure, we have made conservative assumptions for the fracturing strain of individual concrete and steel fibers, thus leading to the absence of any clear plastic plateau in the capacity curve. Despite this, DL will still be shown to govern the design. Figure 3 (left) also shows the bilinear idealization of the capacity curve, deliberately chosen to cross the pushover curve at the point where the structure first reaches the code-prescribed maximum interstory drift of $\theta_{I D R}^{\text {lim, } D L}$. A bilinear fit that significantly deviates from the pushover curve in the nominally elastic range could induce considerable bias in the estimated yield displacement. As can be seen in Fig. 3 (left), both the displacement and the base shear at the yield point were determined equal to $\delta_{y}=0.217 \mathrm{~m}$ and $V_{y}=1479.44$ $\mathrm{kN}$ respectively while the effective period of the structure can be defined as:

$$
T_{\text {eff }}=T_{e l} \cdot \sqrt{\frac{K_{i}}{K_{e f f}}}
$$

where $K_{i}=12285.32 \mathrm{kN} / \mathrm{m}$ and $K_{\text {eff }}=6809.53 \mathrm{kN} / \mathrm{m}$ are the initial and effective lateral stiffness of the frame, respectively, resulting to an effective period of $T_{\text {eff }}=1.656 \mathrm{~s}$.
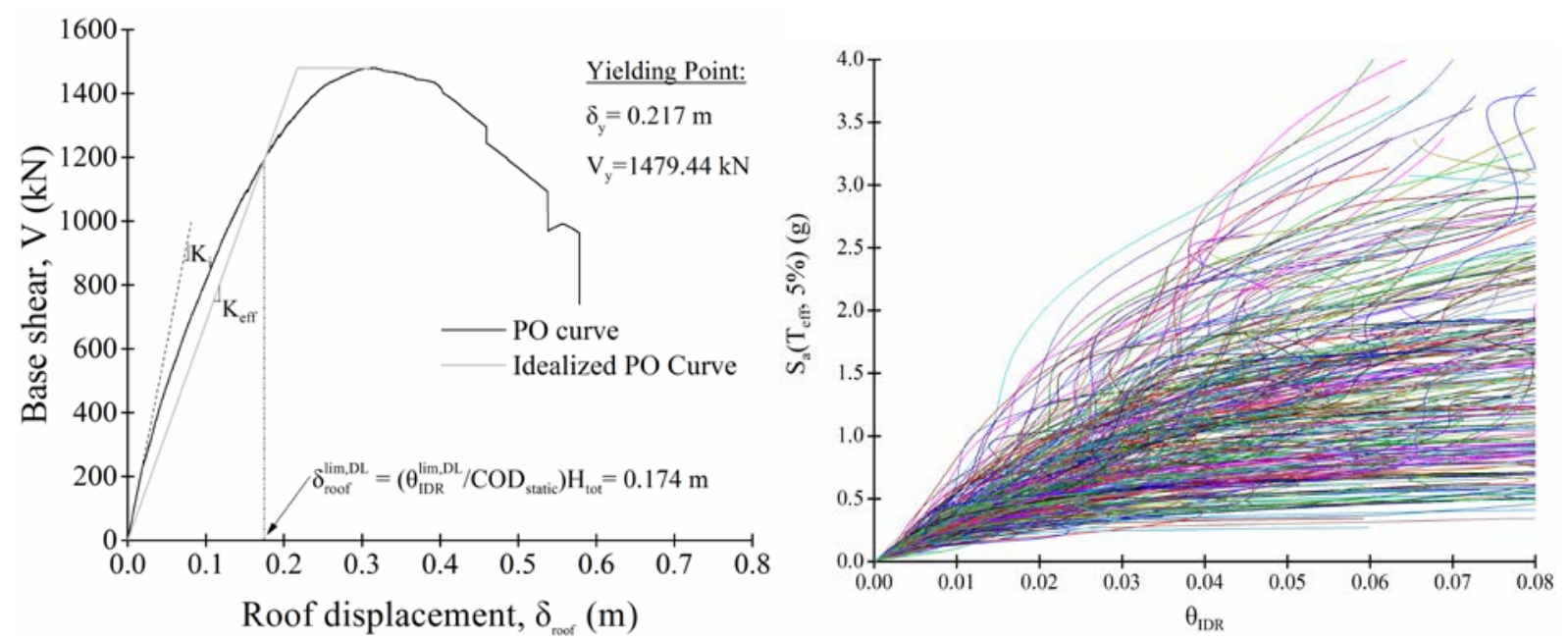

Figure 3. Pushover curve along with its bilinear idealization (left) and 300 IDA curves (right) for the initial code-compatible design of the 8-story RC building. 

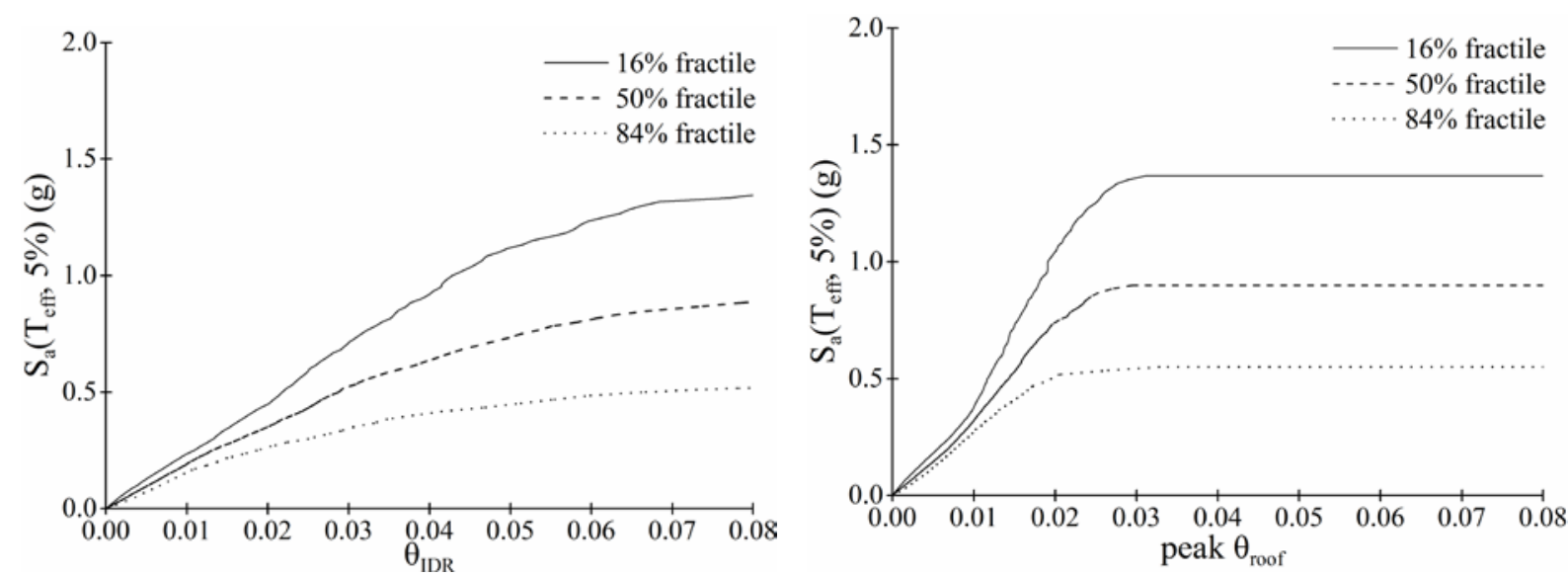

Figure 4. Summary (16\%, $50 \%$ and $84 \%$ fractiles) of the IDA curves for the code-compatible designed 8-story, RC space frame system: $S_{a}\left(T_{\text {eff }}\right)$ versus $\theta_{\text {IDR }}$ (left), and $\theta_{\text {roof }}$ (right).

Moreover, an extensive set of 300 IDA curves, corresponding to the seismic motions used in this study, are presented in Fig. 3 (right) in terms of the maximum, over the time and the stories, interstory drift ratio, $\theta_{I D R}$, and $S_{a}\left(T_{e f f}, 5 \%\right)$ as the IM. It can be seen that IDA curves display a wide range of structural behavior, showing non-trivial record-to-record variability even below the nominal yield point due to extensive section cracking. Figure 4 shows the $16 \%, 50 \%$ and $84 \%$ fractile IDA curves in terms of the maximum interstory drift, $\theta_{I D R}$, and the peak roof drift, $\theta_{\text {roof. }}$ Performance assessment also requires a comprehensive site hazard representation, usually provided by the seismic hazard surface for spectral acceleration, i.e., a (3D) plot of the MAF of exceeding any level of the $S_{a}(T)$ for varying range of structural periods, $T$ (Fig. 5, left). Cutting vertically at given periods produces the familiar hazard curves while cutting horizontally at predefined values of MAF, the corresponding uniform hazard spectra (UHS) are provided (Fig. 5 right).
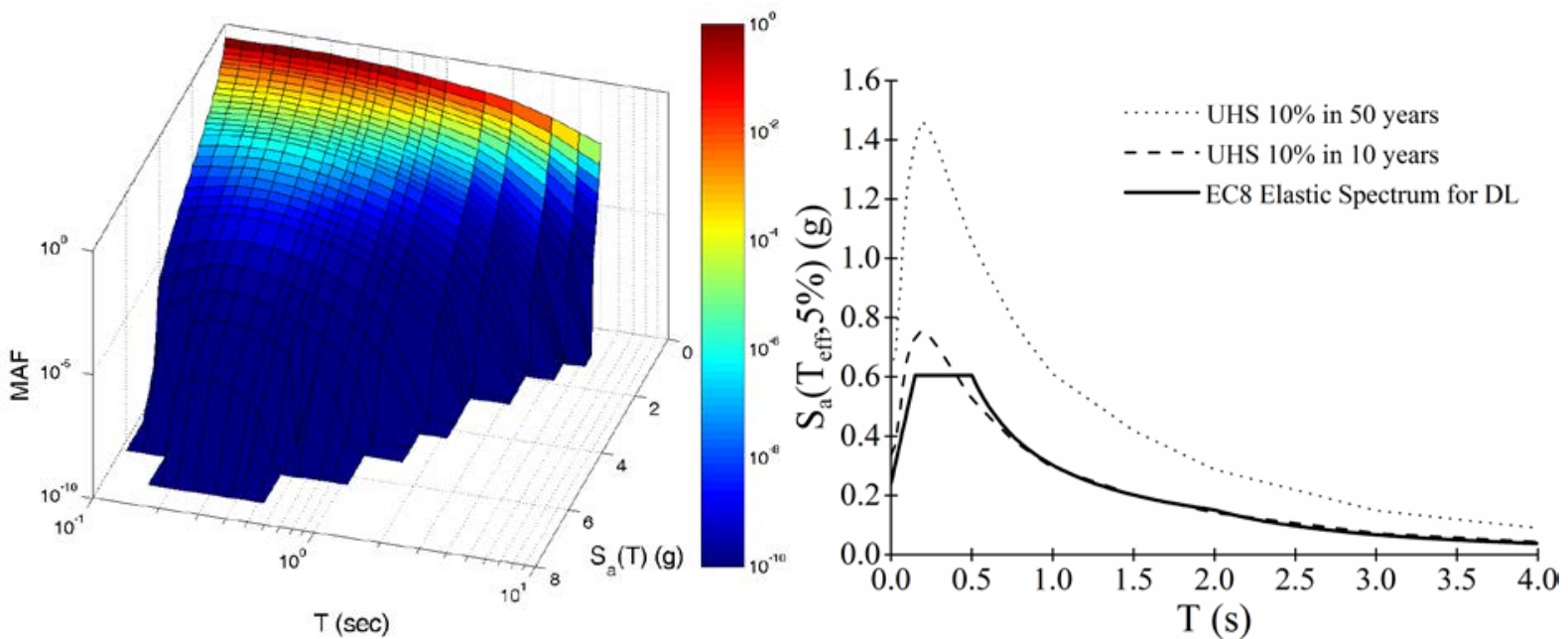

Figure 5. $S_{a}$ hazard for the site: 3D plot of spectral acceleration hazard surface (left) and corresponding uniform hazard spectra plotted against the EN1998-1 elastic design spectrum appropriately reduced for DL checking (right).

As the conventional code design software can only utilize the smooth design spectra as input and in order to ensure a fair basis for assessment and subsequent YFS design, the site hazard was selected so that the $10 \%$ in 10 years UHS matches the site design spectrum as reduced (by the code-imposed factor, $v=0.40$ ) for the governing DL checking, at least in the region of interest of moderate and long periods. The results appear in Fig. 5 (right) showing 
the DL Eurocode spectrum against the two UHS corresponding to Eurocodes-imposed performance objectives: (a) Damage Limitation, DL, with $P O_{, D L}=-\ln (1-0.10) / 10=0.0105$ or $10 \%$ in 10 years probability of exceedance, and (b) Life Safety (or non-collapse requirement) with $P O_{, L S}=-\ln (1-0.10) / 50=0.0021$ or $10 \%$ in 50 years probability of exceedance. Although this match is not optimal for periods lower than $0.5 \mathrm{~s}$, where the higher modes of the structure lie, this is not considered an issue neither for assessment nor for design. First of all, smoothed design spectra often underpredict $S_{a}(T)$ in the constant acceleration "plateau". More to the point, the influence of higher modes is of minor significance and after all, both assessment and YFS design will be based only on the first effective period, $S_{\alpha}\left(T_{\text {eff }}\right)$ hazard, without any specific allowance for the UHS shape below 0.5s. Given the seismic hazard already adjusted to the EN1998-1 design spectrum (Fig 5) and the fragility analysis results from the IDA (Figs. 3 right and 4) of the case study building, the MAF of exceeding the DL state can be calculated [18]. This calculation provides the actual MAF of exceeding the PO of interest, since it incorporates site-specific hazard, being convoluted with the IDA-assessed structural performance of the specific 8-story building that has been designed according to Eurocode prescriptions. Hence, the comparison of the actual MAF value with the maximum codeallowable one for a common PO reveals whether (or not) the code-compatible design of a structure fulfills the performance criterion of interest. Especially, considering only record-torecord variability, the actual MAF of exceedance of $\theta_{I D R}^{\mathrm{lim}, D L}=0.75 \%$ was numerically calculated equal to 0.0174 , which is significantly higher (by 65\%) than the maximum allowable code-imposed MAF for the DL, i.e., $P O_{, D L}=0.0105$. Had we also introduced an increased dispersion due to additional (e.g. epistemic) uncertainties, the discrepancy would have been even higher. The adoption of a different limiting interstory drift ratio (e.g., $\theta_{I D R}^{\lim , D L}=0.50 \%$ that is prescribed by EN1998-1 when non-ductile infills are used) would still lead to non-conformance with the performance-based criterion since its fulfillment is mainly affected by the dispersion in the response and the seismic hazard at frequent earthquakes [19], typically disregarded in the design process. Thus, despite the fact that the typical, codeprescribed design process is satisfied for the particular case-study building (i.e., for the sake of proof, all the conventional code-mandated criteria about the stiffness, strength, limitations in the displacements as well as the reinforcement and the capacity design were satisfied by the initial design), the design performance objectives are not met. In other words, the design achieved by the code approach may be legally sound, yet it does not perform as the code itself intended failing the design performance objectives, which are implied but not really tested in the common design process.

\subsection{YFS-based redesign of the case study building}

Two different phases can be identified regarding the application of YFS for the PBSD of the space frame structure: (a) the definition of the design requirements based on the ESDOF approximation of the YFS framework and (b) the redesign of the MDOF structure according to the YFS results. In the ensuing, the aforementioned phases are thoroughly described and, depending on the results obtained, the accuracy of the proposed methodology for PBSD is evaluated in the next section.

\subsubsection{Phase 1: Design requirements based on the ESDOF approximation. This}

initial phase consists of determining the (essentially ESDOF) design requirements primarily in terms of the system's yield strength (or yield strength coefficient), $C_{y}$, and the structural 
period, $T$, both of them tied together via the yield displacement, $\delta_{y}$ (Eq. 2). In order to define the essential ingredients of the proposed methodology, the site hazard surface of Fig. 5 was adopted while a bilinear elastic-plastic backbone shape was considered to model system's response. Damping ratio was set to $5 \%$. For the yield displacement, a simple initial estimate would be $0.5-0.6 \%$ of the building height (or $\delta_{y}=0.16-0.20 \mathrm{~m}$ ) based on Aschheim [15], where $\delta_{y}$ is expressed as a function of geometrical and material properties for different structural configurations. Similar expressions, already proposed in the literature (a relevant review is shortly provided in [36]), could be also used to determine the yield displacement. However, in our case, the pushover curve (Fig. 3, left) allows us to directly determine an accurate result of $\delta_{y}=0.217 \mathrm{~m}$, not far from the aforementioned simpler approximation. The estimate for the ESDOF system's yield displacement is defined as:

$$
\delta_{y}^{*}=\frac{\delta_{y}}{\Gamma}
$$

where $\Gamma$ is the first-mode participation factor, equal to 1.30 for the case study building. However, this definition of $\Gamma$ neglects the higher modes' contribution to the dynamic response of this flexible frame system. Thus, a "multi-modal" approximation can also be considered to reflect the higher modes effect on ESDOF's value of $\delta_{y}^{*}$. To this end, the parameter $G$ was introduced as a multi-modal substitute of the first-mode participation factor $\Gamma$ by inverting the widely used formula to obtain the target displacement in nonlinear static approaches [37]:

$$
G=\frac{\delta_{\text {roof }}}{S_{a}\left(\mathrm{~T}_{\text {eff }}\right)} \frac{4 \pi^{2}}{T_{\text {eff }}^{2}}
$$

In order to define the roof drift, $\delta_{\text {roof }}$, which should include the influence of all modes of vibration, one may perform, for example, one or more modal response spectrum analyses (MRSA) of the building at an intensity level of an arbitrary low value $S_{a}\left(T_{\text {eff }}\right)$, using either the design spectrum or a set of ground motions. In our case, the readily available data from IDA was utilized. Specifically, the "nominally elastic" part of the $50 \%$ fractile IDA curve (Fig. 4, left) was utilized and an average value of $G$ equal to 1.64 was determined for $0 \leq S_{a}\left(T_{\text {eff }}\right) \leq 0.30 \mathrm{~g}$. Such a higher value of $G$ instead of $\Gamma$ (up to 26\%) is attributed to the higher modes effects, captured efficiently by the dynamic analysis response results. Thus, the substitution of $\Gamma$ with $G$ in Eq. (5) led to a somewhat lower estimate for the yield displacement, $\delta_{y}^{*}$, equal to $0.129 \mathrm{~m}$.

Moreover, a set of performance objectives, comprising limiting ductility values and the corresponding allowable MAFs of exceedance, is required. Akin to design code basis, an ultimate limit-state, Life Safety (LS), was adopted for $10 \%$ in 50 years at limiting ductility of $\mu_{L S}=4.50$. This is the pure ductility implied by EN1998-1 provisions [23] to define the basic value, unmodified by overstrength, of the behavior factor for frame systems designed for DCH. For informational purposes and to show the capability of YFS to incorporate an arbitrary number of POs, we also included a PO that is unrelated to the code with a ductility of 5.8 at $3 \%$ in 50 years as a near-collapse indicator. Moreover, to limit damages under frequent earthquakes of low intensity, the Eurocodes-imposed serviceability interstory drift limit of $\theta_{I D R}^{\mathrm{lim}, D L}=0.75 \%$ was considered herein along with the corresponding MAF of 0.0105 . The associated limiting ductility for DL can be expressed as: 


$$
\mu_{D L}=\frac{\delta_{D L}}{\delta_{y}}=\frac{\theta_{\text {roof }}^{\text {lim } D L}}{\theta_{\text {roof }, y}}
$$

where $\theta_{\text {roof,y }}$ is the roof drift at yield equal to $\delta_{y} / H_{\text {tot }}=0.665 \%$. The limiting roof drift ratio, $\theta_{\text {roof }}^{\text {lim,DL}}$, for the 8-story building that corresponds to the code-mandated value of $\theta_{I D R}^{\lim , D L}=0.75 \%$ can be estimated via the coefficient of distortion (COD) [11], defined as the ratio of the maximum interstory drift $\theta_{I D R}$ over the peak roof drift $\theta_{\text {roof }}$, in this case estimated at or near the nominal yield point. $C O D$ is always larger than (or rarely equal to) 1.0 and it characterizes the non-uniformity of a building's deformation along the height. This parameter can be utilized to estimate $\theta_{\text {roof }}^{\text {lim, } D L}$ as:

$$
\theta_{\text {roof }}^{\lim , D L}=\frac{\theta_{I D R}^{\lim , D L}}{C O D}
$$

For first-mode dominated structures, the $C O D$ can be easily derived by inspection of the first-mode shape [38] while reasonable COD estimates for either steel or RC structural systems are available elsewhere [39-41]. Further refinement in the COD value can be also achieved when its definition is based on actual inelastic static or even dynamic analysis results. Along these lines, Fig. 6 presents the $C O D_{\text {static }}$ as a function of the roof drift ratio, $\theta_{\text {roof }}$, attained during the successive load steps from the pushover analysis of the space frame model. The subscript static is associated with the inelastic static analysis method used to determine this parameter. A $C O D_{\text {static }}$ of 1.40 is estimated by averaging the $\theta_{I D R}$ over $\theta_{\text {roof }}$ ratios in the initial, nominally elastic part of the response, and hence, the limiting roof drift ratio is calculated, through Eq. (8), equal to $\theta_{\text {roof }}^{\mathrm{lim}, D L}=0.536 \%$.

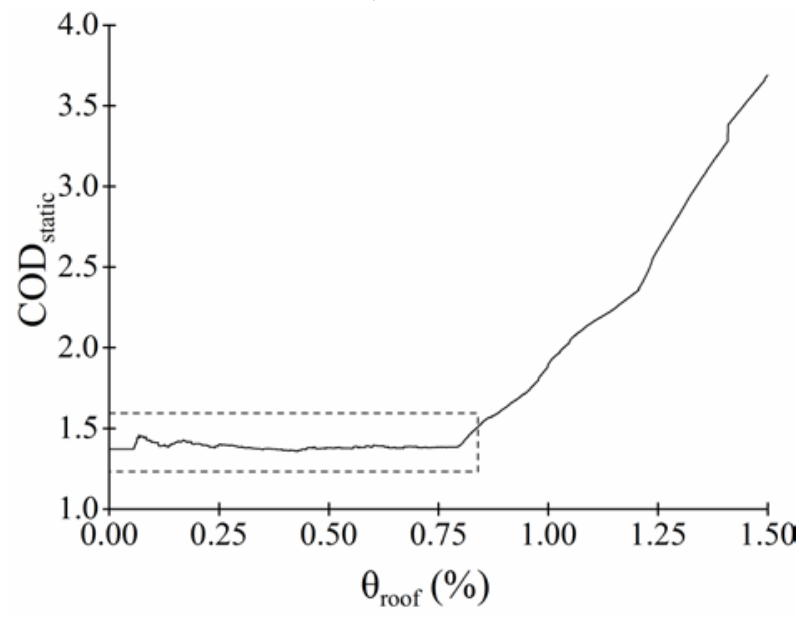

Figure 6. Coefficient of distortion (COD) calculation based on the pushover analysis for the initial code-compatible design of the 8-story RC building.

Similarly to our previous discussion on $G$ and $\Gamma$, the contribution of the higher modes can also affect the $C O D$. Therefore, a "multi-modal" approximation was considered again and the adopted $C O D_{\text {dynamic }}$ was derived by the IDA results for the system's nominally elastic range. Particularly, for given values of $S_{a}\left(T_{\text {eff }}\right)$, both $\theta_{I D R}$ and $\theta_{\text {roof }}$ were determined from the median IDA capacity curve provided in Fig. 4 and a $C O D_{\text {dynamic }}$ equal to 1.517, slightly higher than $C O D_{\text {static }}$, was obtained by averaging the $\theta_{I D R}$ over $\theta_{\text {roof }}$ ratios. Eventually, using $C O D_{\text {dynamic }}$ with Eqs. (7) and (8), the limiting ductility for DL is estimated as $\mu_{D L}=0.759$. 
Within the YFS framework, the definition of the performance levels also involves choosing the magnitude of the related additional (typically epistemic) uncertainty, $\beta_{U}$. Higher epistemic uncertainty is, in general, associated with deficient knowledge about the actual structural capacity and demand. Normally, lower values of epistemic uncertainty are related to the elastic and nearly elastic response of structural systems while high levels of inelastic deformations are associated with increasing values for $\beta_{U}$. In the current study, the contribution of epistemic uncertainty is deliberately disregarded to avoid conservative biasing of the output of YFS. In an actual design setting, though, such uncertainty and the corresponding user-selected level of confidence, required in achieving each PO, become essential safety factors that enhance the method's robustness. Instead, record-to-record variability will be addressed only to achieve a fair basis for comparison vis-à-vis the code. To this point, as a bilinear ESDOF approximation predicts exactly zero record-to-record variability below the yield point (where the DL checking is performed), a logarithmic dispersion of $30 \%$ is applied to the displacement response given IM distribution in order to match the IDA prediction at the nominal yield point. This is taken to remain relatively constant for higher intensities (thus appropriately increasing the ESDOF estimate of recordto-record variability to match the MDOF results) and linearly decrease towards zero for lower IM values. It is notable that the IDA-assessed dynamic response results (Figs. 3 right and 4) led to an estimation for the logarithmic dispersion of $24.2 \%$ (being more than $80 \%$ of the total dispersion considered herein) while an increase of $25 \%$ was eventually applied (i.e., $1.25 \cdot 24.2 \%=30 \%$ ) to account for the model uncertainty.

After acquiring all the aforementioned ingredients involved into the YFS calculation, the YFS contours were derived (Fig. 7) with the use of a numerical algorithm encoded in software [42]. As anticipated for a flexible, moment resisting frame, DL governed and the critical yield strength coefficient was found to be $C_{y}=0.336$. The corresponding period is $T_{Y F S}=1.243 \mathrm{~s}$ (Eq. 2) while the required base shear strength at the yield can be determined as:

$$
V_{\mathrm{y}, Y F S}=a_{1} C_{y} W
$$

where $a_{1}$ is the first mode mass participation factor and $W=7469 \mathrm{kN}$ (mass of $761.35 \mathrm{t}$ ), represents the total weight of the case study building. Typically, $a_{1}$ is assumed to be equal to the ratio of the first mode effective mass over the total (e.g., FEMA-273 [2]), which comes up to 0.82 for the 8-story building. In this case, though, there is enough data to estimate its actual value for the initially designed frame model. To do so, the $C_{y}$ value that corresponds to the initial design was firstly determined by rearranging Eq. (2): $C_{y \text {,actual }}=\delta_{y}^{*} 4 \pi^{2} / g T_{\text {eff }}^{2}=0.19$, which is obviously less than the YFS-based demand for $C_{y}$ equal to 0.336 . Then, by solving Eq. (9) for $a_{1}$ and using the base shear at yield $V_{y}=1479.44 \mathrm{kN}$ of the initial design (determined via the pushover analysis, see Fig. 3, left), one finds $a_{1}=C_{y, \text { actual }} W / V_{y}=0.19 \cdot 7469 / 1479.44=0.97$. This value for the first mode mass participation factor, which is nearly equal to unity, means that using the entire mass of the structure, rather than the first mode mass only, provides a more accurate equivalent SDOF for this midrise structure. This conclusion cannot be generalized, yet one cannot fail to notice that it is in contrast to the recommendations of existing guidelines and it merits additional research. Eventually, using the actual value for $a_{1}$, the required (YFS-derived) base shear at the yield was estimated as $V_{y, Y F S}=2434.25 \mathrm{kN}$.

In summary, both the shorter structural period and the higher yield base shear, required by the proposed methodology, i.e., $T_{Y F S}=1.243 \mathrm{~s}$ versus $T_{\text {eff }}=1.656 \mathrm{~s}$ and $V_{y, Y F S}=2434.25 \mathrm{kN}$ versus $V_{y}=1479.44 \mathrm{kN}$, signify that this multi-story, moment resisting RC space frame has to be redesigned to become stiffer and with higher strength capacity as a means to satisfy the 
stated POs. This necessity for redesigning the frame structure, highlighted by the YFS application, is also in full agreement with the outcome of the performance assessment of the building (§3.2), where the actual MAF achieved exceeded by $65 \%$ the maximum allowable MAF related to the dominant DL performance level.

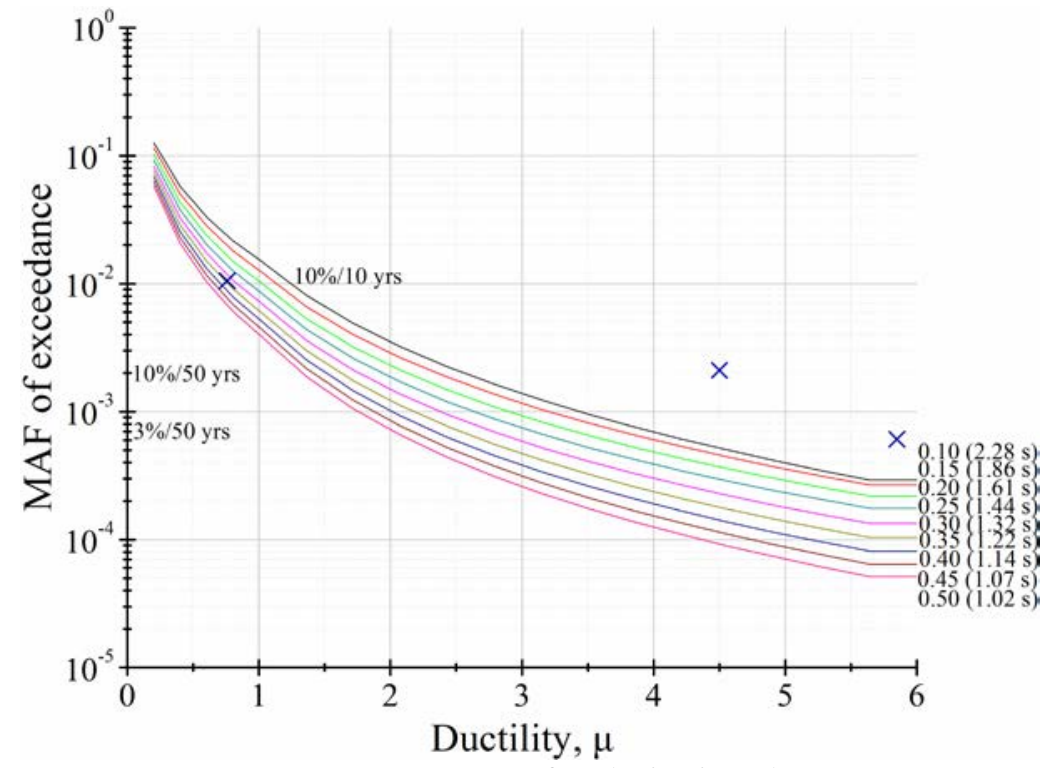

Figure 7. YFS contours at $C_{y}=0.10,0.15, \ldots, 0.50$ for designing the 8-story, RC space frame system, subjected to the adopted seismic hazard. " $x$ " symbols represent the POs considered herein $(\mu=0.759$, 4.5, 5.8 at $10 \%$ in $10 \mathrm{yrs}$ as well as $10 \%$ and $3 \%$ in 50 yrs exceedance rates, respectively). The DL objective ( $10 \% / 10$ yrs) governs with $\mathrm{C}_{\mathrm{y}} \approx 0.336$ and the corresponding period is $\mathrm{T} \approx 1.243 \mathrm{~s}$.

3.3.2 Phase 2: MDOF redesign . For the redesigned building according to YFS (a) the structural (cracked) period needs to be close to $1.24 \mathrm{~s}$ and (b) the actual base shear strength (including the effect of overstrength) should be in the vicinity of $2435 \mathrm{kN}$. Thus, it is obvious that structural members with larger cross-sections and potentially higher reinforcement ratios should be chosen in order the case study building to satisfy the requirements. As the design spectrum is the primary means of introducing seismic loading requirements into most design software, such programs can be still used by rescaling the spectrum to correspond to an increased and YFS-modified peak ground acceleration $\alpha_{g R, Y F S}$ (rather than the inadequate $a_{g R}=0.36 \mathrm{~g}$ ) that can appropriately convey the need for added strength and stiffness.

To achieve this, one needs to consider the base shear strength of the YFS designed building. In terms of YFS-derived quantities, this can be expressed as $V_{y, Y F S} / \Omega=C_{y} W / \Omega$, where $\Omega$ is the actual overstrength ratio of the structure. Had this building been ideally proportioned according to a spectral value of $S_{a Y F S}\left(T_{Y F S}, 5 \%\right)$, this could also be written as $S_{a Y F S}\left(T_{Y F S}, 5 \%\right) W / g / q$, thus:

$$
\frac{S_{a Y F S}\left(T_{Y F S}, 5 \%\right)}{g q}=\frac{C_{y}}{\Omega}=\frac{V_{y, Y F S}}{W}
$$

Appropriate values for $\Omega$ can be found in the literature. Then solving for $S_{a Y F S}\left(T_{Y F S}, 5 \%\right)$ and comparing with the corresponding value at the same period of the initial design spectrum allows estimating an appropriate scale factor. Alternatively, as the static pushover results of the initially designed building are available, one may estimate the actual $\Omega$ as 


$$
\Omega=\frac{V_{y}}{V_{\text {design }}}=\frac{V_{y} g}{S_{\text {adesign }}\left(T_{\text {eff }}, 5 \%\right) a_{1} W}
$$

The different parts of the design spectrum can be generally represented as $S_{a}(T)=A / T^{\text {c }}$, where $A$ is the design spectral acceleration at an "anchoring" period (typically at the start of each segment) and $c=0,1,2$, for the constant acceleration, velocity and displacement segments, respectively. Then, the yield base shear of the initial design is $V_{y}=$ $A_{\text {des }} /\left(T_{\text {eff }}\right)^{c} \cdot \Omega \cdot W / g$ while the same quantity for the YFS design (assuming the same values of weight of the structure and its overstrength before and after the YFS-based redesign) becomes $V_{y Y F S}=A_{Y F S} /\left(T_{Y F S}\right)^{c} \cdot \Omega \cdot W / g . A_{d e s}$ and $A_{Y F S}$ are the spectral acceleration values at an "anchoring" period. By dividing these two equations, one finds:

$$
A_{Y F S}=\left(\frac{T_{Y F S}}{T_{e f f}}\right)^{c} \frac{V_{y, Y F S}}{V_{y}} A_{d e s}
$$

For the case at hand, the moderate period range corresponds to $c=1$ while both anchoring values can be expressed for the Eurocode spectrum as the same constant times the corresponding peak ground acceleration, i.e., $A_{d e s}=A_{o} \cdot a_{g R}$ and $A_{Y F S}=A_{o} \cdot \alpha_{g R, Y F S}$, leading to:

$$
a_{g R, Y F S}=\frac{T_{Y F S} V_{y, Y F S}}{T_{e f f} V_{y}} a_{g R}
$$

All the parameters involved in the right side of Eq. (13) have been already determined for the case study building and $a_{g R, Y F S}$ was calculated at $0.45 \mathrm{~g}$, consistent with an $a_{g R, Y F S} / a_{g R}=1.25$ scaling factor to be applied to the original design spectrum. It is notable that the main idea about introducing the modified $\alpha_{g R, Y F S}$ parameter is to facilitate the redesign, since using the code-prescribed modal response spectrum analysis based on the $\alpha_{g R, Y F S}-$ scaled design spectrum is expected to navigate rapidly the engineers choosing a redesign solution that (a) has structural period and yield base shear identical to the ones derived by the YFS application and (a) the POs, prescribed by the code, are addressed successfully.

Given the updated design spectrum as well as the aforementioned requirement for limiting the effective period, a YFS-consistent design of the 8-story building is readily obtained. All other design variables (e.g., material properties, exposure class, soil conditions, structure's importance, ductility class, gravity loading variables, floor system) were kept unchanged. As expected, the higher demand in terms of stiffness and strength dictated the use of larger crosssections for both columns and beams. Square cross-sections of $0.70 \mathrm{~m}$ x $0.70 \mathrm{~m}$ were used for the columns (compared to $0.60 \mathrm{~m} \times 0.60 \mathrm{~m}$ initially) while the cross-section area of the beams is $0.75 \mathrm{~m} \times 0.55 \mathrm{~m}$ or 1.72 times larger than the one corresponding to the initial design. Moreover, the redesigned building was controlled by the code-imposed drift limitations. However, the maximum interstory drift estimated by MRSA is now $0.58 \%$, considerably lower than the $0.75 \%$ limit imposed by EN1998-1 for DL. Due to the higher stiffness, $P-\Delta$ effects became negligible and the interstory drift sensitivity coefficient, $\theta$ (Eq. 3), was estimated to be lower than 0.10 for each story level. Both the longitudinal and transverse steel reinforcement ratios were found to be slightly higher than the minima required according to code.

\subsection{Performance assessment of the redesigned building}

Akin to the procedure described earlier (§3.2), both IDA and static pushover analysis were 
performed for a 2D model of the internal frame of the redesigned building using OpenSees [27]. Material properties and modeling assumptions were kept the same as those of the initial design. The eigenvalue analysis of the redesigned frame model resulted in a fundamental (purely elastic) vibration period of $0.889 \mathrm{~s}$, which is $28 \%$ shorter than the first-mode period related to the initially designed frame model (i.e., $T_{1}=1.233 \mathrm{~s}$ ). Moreover, the periods associated with the second and third mode of the redesigned frame were estimated at $0.290 \mathrm{~s}$ and $0.164 \mathrm{~s}$, respectively.
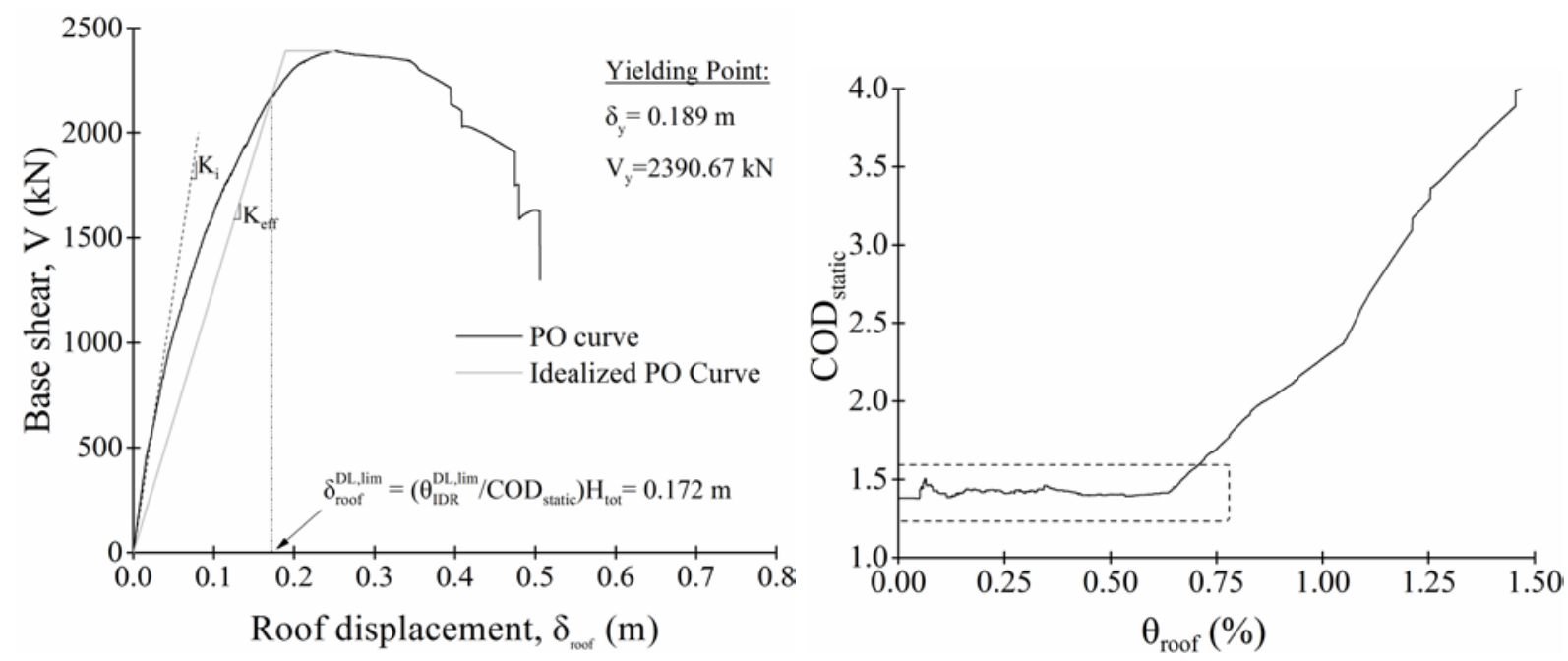

Figure 8. Pushover analysis of the YFS-based, redesigned 8-story, RC space frame system: Capacity curve and its bilinear idealization (left), COD calculation (right).
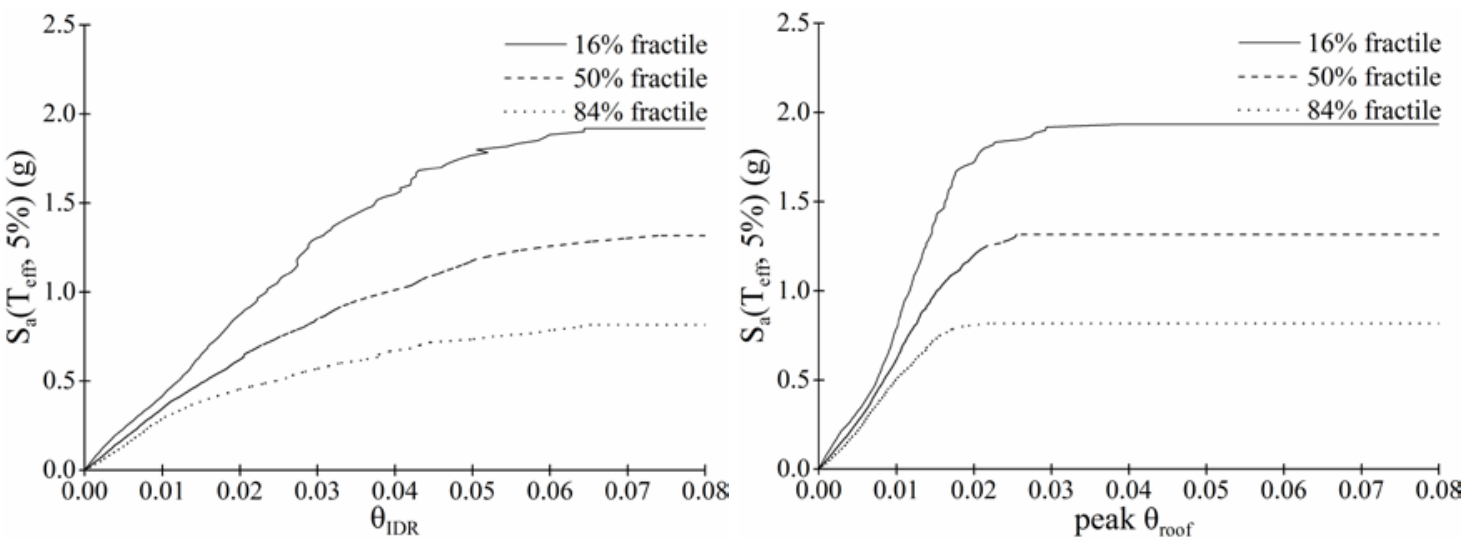

Figure 9. Summary (16\%, 50\% and 84\% fractiles) of the IDA curves for the YFS-based, redesigned 8story, RC space frame system: $S a\left(T_{\text {eff }}\right)$ vs $\theta_{I D R}\left(\right.$ left) and $\theta_{\text {roof }}$ (right).

A first-mode load pattern was assumed for the pushover analysis and the resulting capacity curve is presented in Fig. 8 (left). Inelastic static analysis results, plotted in terms of $C O D_{\text {static }}$ vs $\theta_{\text {roof }}$ (Fig. 8, right), were also utilized to determine the $C O D$ parameter used for idealizing the pushover curve. For the redesigned structure, $C O D_{\text {static }}$ was estimated as 1.42; hence, the DL-related limiting roof drift ratio was calculated, in line with Eq. (8), equal to $\theta_{\text {roof }}^{\text {lim, } D L}=0.528 \%$, which is marginally lower than the $0.536 \%$ corresponding to the initial design. The roof displacement and the base shear at the yield point were $0.189 \mathrm{~m}$ and $2390.67 \mathrm{kN}$ respectively, the latter varying only by $1.8 \%$ from the YFS-based, target base shear (unmodified by overstrength) for the redesigned structure (i.e., $V_{\text {YFS }}=2434.25 \mathrm{kN}$ ). 
Finally, the resulting effective period, calculated according to Eq. (4), was $T_{\text {eff }}=1.246 \mathrm{~s}$, almost identical to the required $T_{Y F S}=1.243 \mathrm{~s}$. Thus, a single iteration was needed to achieve a structural redesign that met the objectives imposed by the YFS framework.

It is only pending to ascertain if the redesigned frame, according to the YFS-based requirements, satisfies the performance objectives imposed by EN1998-1 provisions. To this end, MAF calculations were carried out on the basis of IDA results for the redesigned structural system using the aforementioned set of 300 seismic motions. Figure 9 shows the summarized IDA results in terms of $\theta_{I D R}$ (left) and $\theta_{\text {roof }}$ (right). Comparing Figs. 4 and 9, and despite the slight difference in period, it becomes obvious that the redesigned structure is associated with significantly higher earthquake resistance capacity, the latter being also verified by comparing the pushover curves for the two designs (Figs. 3 and 8). Accordingly, the actual MAF of exceedance of $\theta_{I D R}^{\mathrm{lim}, D L}=0.75 \%$ for the redesigned building was calculated to be equal to 0.0097 , only slightly lower than the maximum allowable $\lambda_{\mathrm{DL}}=0.0105$. In other words, the YFS approach achieved a near-perfect compliance with the stated performance objectives within a single step. Still, it should be noted that the approximations involved in the YFS application could also have produced a MAF result slightly higher than $\lambda_{\text {DL }}$. A less elaborate application of YFS, using for example textbook estimates for $\Omega, C O D$ and $\delta_{y}$ rather than a static pushover analysis, or tackling an asymmetric structure that is not well captured by an ESDOF system, would also lead to larger discrepancies, either conservative or unconservative. This is where the introduction of epistemic uncertainty and the use of appropriate confidence level estimates for $C_{y}$ and $T$ needs to come into play. The magnitude of epistemic uncertainty conveys our incomplete knowledge about the effect of assumptions and approximations to the model while the selection of a confidence level (say within 5095\%) creates a tunable safety factor that can be chosen to be commensurate to the consequences of each PO violation [17]. In contrast to the indiscriminate introduction of conservativeness via the mechanisms employed in current codes, the above format accurately propagates all such uncertainties to the design quantities, ensuring compliance with the userselected level of reliability.

\subsection{YFS-based verification of the redesigned building}

Heretofore, the case study building was: (a) designed according to code provisions, (b) assessed through a probabilistic framework that showed the insufficiency of the initial design to meet the code-imposed POs, (c) redesigned on the basis of the YFS method and (d) assessed again to reveal the successful YFS-based redesign. To close the loop, the YFS framework will be reapplied for the redesigned building with the sole purpose of checking the convergence of the process. Similarly to the procedure described in $\S 3.3$ (Phase 1), the ESDOF system of the redesigned space frame system has to be defined and the corresponding yield displacement, $\delta_{y}^{*}$, can be determined using Eq. (5). The pushover analysis of the redesigned building led to an estimation for the yield displacement of $\delta_{y}=0.189 \mathrm{~m}$ (Fig. 8, left) while the parameter $G$, being the multi-modal approximation of the first-mode participation factor $\Gamma$, was calculated to be 1.645 based on the $50 \%$ fractile IDA curve (Fig. 9, left). Hence, a $\delta_{y}^{*}=0.114 \mathrm{~m}$ was determined. The IDA results for the redesigned building (Fig. 9) were also used to determine the $C O D_{\text {dynamic }}$ parameter, which is necessary to derive the limiting ductility corresponding to the DL level, $\mu_{D L}$ (Eq. 7). A value for $C O D_{\text {dynamic }}$ equal to 1.479 led to $\mu_{D L}=0.893$. The LS-related limiting ductility value as well as the additional 
variability to account for the increased record-to-record dispersion of the MDOF vis-à-vis the ESDOF system were kept the same as in the previous application of the YFS framework.

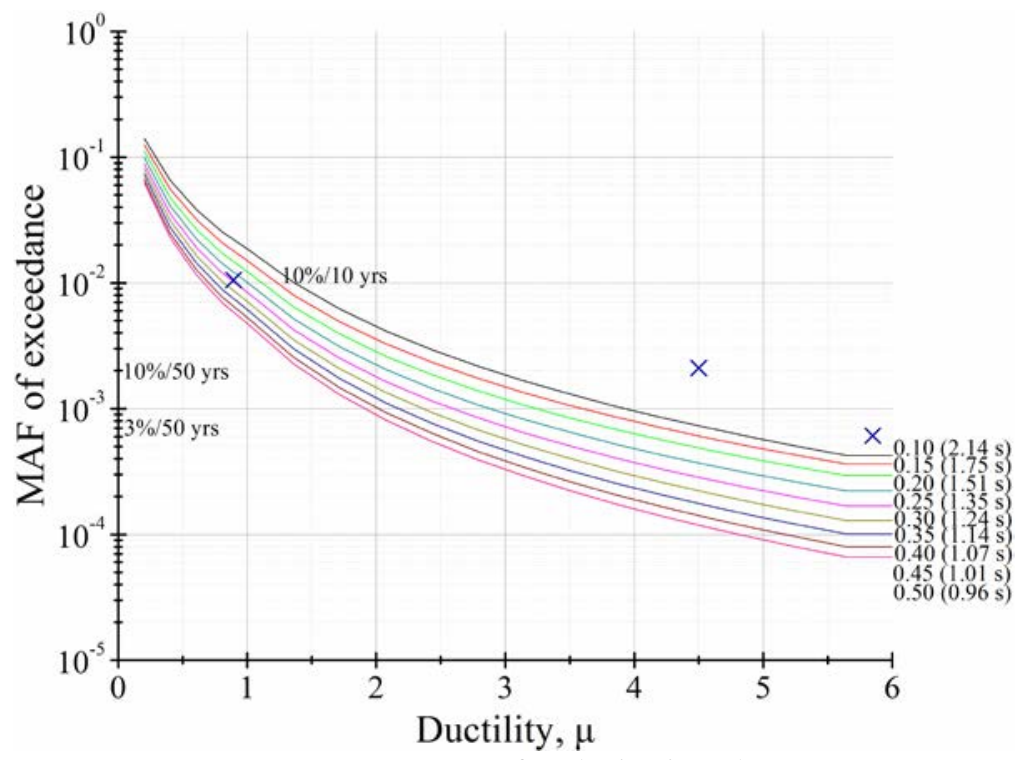

Figure 10. YFS contours at $C_{y}=0.10,0.15, \ldots, 0.50$ for designing the 8 -story, RC space frame system, subjected to the adopted seismic hazard. " $x$ " symbols represent the POs considered herein $(\mu=0.893$, 4.5, 5.8 at $10 \%$ in $10 y r s$ as well as $10 \%$ and $3 \%$ in 50 yrs exceedance rates, respectively). The DL objective ( $10 \% / 10$ yrs) governs with $\mathrm{C}_{\mathrm{y}} \approx 0.293$ and the corresponding period is $\mathrm{T} \approx 1.251 \mathrm{~s}$.

Based on the parameters determined above, the critical yield strength coefficient, $C_{y}$, was calculated to be 0.293 (Fig. 10). The corresponding period is $1.251 \mathrm{~s}$ (Eq. 2), almost identical to both the effective period of the redesigned space-frame model ( $T_{\text {eff }}=1.246 \mathrm{~s}$ ) and the period demand determined by the initial application of the YFS framework $\left(T_{Y F S}=1.243 \mathrm{~s}\right)$. As expected, DL again governs the structural design. Furthermore, the actual yield strength coefficient was estimated $C_{y, \text { actual }}=\delta_{y}^{*} 4 \pi^{2} / g \mathrm{~T}_{\text {eff }}^{2}=0.295$, which is nearly identical with the YFSbased $C_{y}$. Eventually, the required base shear strength at the yield, $V_{y, Y F S}$, was estimated using Eq. (9). To this end, the total weight of the redesigned frame, $W$, was calculated as $8624 \mathrm{kN}$ (mass of $879.085 \mathrm{t}$ ) and the first mode mass participation factor, $a_{1}$, was considered equal to 1.0. Hence, $V_{y, Y F S}=2526.78 \mathrm{kN}$ and only a marginal difference of $3.6 \%$ was observed in comparison to the previous application of the YFS method. Therefore, it can be seen that the proposed approach shows rapid and robust convergence in this case determining the parameters related to building's redesign (i.e., structural period, yield strength coefficient and base shear) after a single step. The main numerical results of the different steps from the initial design of the 8-story building up to the final YFS-based verification of the redesigned building, are summarized in Table 1.

Table 1. Main numerical results from the different steps included in the YFS case-study.

\begin{tabular}{lcccc}
\hline & $\begin{array}{c}\text { Fundamental } \\
\text { period, } T_{\text {eff }}(\mathrm{s})^{\dagger}\end{array}$ & $\begin{array}{c}\text { Yield base } \\
\text { shear, } V_{y}(\mathrm{kN})\end{array}$ & $\begin{array}{c}\text { Yield strength } \\
\text { coefficient, } C_{y}\end{array}$ & $\begin{array}{c}\text { MAF for DL, } \\
P O_{D L}\end{array}$ \\
\hline $\begin{array}{l}\text { Initial Design } \\
(\$ 3.1, \S 3.2)\end{array}$ & 1.656 & 1479.44 & 0.190 & 0.0174 \\
$\begin{array}{l}\text { YFS-based design } \\
\text { requirements }(\$ 3.3 .1)\end{array}$ & 1.243 & 2434.35 & 0.336 & - \\
$\begin{array}{l}\text { Redesign } \\
(\$ 3.3 .2, \text { \$3.4) }\end{array}$ & 1.246 & 2390.67 & 0.295 & 0.0097
\end{tabular}


YFS-based verification of

the redesign $(\S 3.5)$

$1.251 \quad 2526.78$

0.293

${ }^{\dagger}$ The effective period, $T_{\text {eff }}$ of the space frame model.

\section{OPTIONS FOR SIMPLIFIED APPLICATION}

The yield displacement, $\delta_{y}$, as well as the $C O D_{\text {static }}$ parameter, the latter used to calculate the DL-related limiting roof drift ratio, $\theta_{\text {roof }}^{\mathrm{lim}, D L}$, were determined by taking advantage of the pushover analysis of the building. These rather demanding estimations of $\delta_{y}$ and $C O D_{\text {static, }}$ expected to be waived in a typical design office environment, were deliberately chosen for showcasing herein a YFS application of increased accuracy. For the same reason, results from costly IDA were utilized to obtain as accurate predictions as possible for both $G$ and $C O D_{\text {dynamic }}$, which are the multi-modal approximations of the first-mode participation factor $\Gamma$ and $C O D_{\text {static }}$, respectively. Alternatively, several approaches of varying simplicity can be considered to define the parameters involved in the YFS framework. For the sake of example, the yield displacement can be readily defined using simplified formulae, already proposed in literature that associate $\delta_{y}$ with various geometrical characteristics (e.g., typical floor's or total structure's height, column depth and beam span) as well as structural (e.g., longitudinal reinforcement ratio and column overstrength ratio) and material properties (e.g., yield strain of steel reinforcing bars) [15,36,43-46]. Experts engineering judgement could be even used for a preliminary estimation of the yield displacement since it has been found to be of higher stability for a given structural configuration than the fundamental period [13,15].

Similarly, MRSA along with a higher uncertainty level can be alternatively considered to determine both $G$ and $C O D_{\text {dynamic }}$ instead of their rigorous IDA-based estimation adopted herein. Particularly, MRSA can be performed using either response spectra of appropriately selected earthquake records or just the average spectrum of a set of earthquake motions. Further simplicity can be reached if a code spectrum is utilized to conduct the MRSA. Alternatives of inelastic static analysis to determine the $C O D_{\text {static }}$ parameter were also described earlier in this study (§3.2) However, this gradual decrease in the complexity (and hence accuracy) of the procedures chosen to evaluate both $G$ and $C O D_{\text {dynamic }}$ parameters has to be in line with a relevant increase in the uncertainty considered within the YFS framework. To be more specific, the accuracy deficit incurred by simpler procedures and assumptions adopted during the structural design, can be counterbalanced up to a certain point within the YFS framework by defining higher levels of uncertainty (i.e., epistemic uncertainly, $\beta_{U}$ ) and demanding specific levels of confidence in the results. Eventually, more than a single step of YFS redesign may be needed for convergence. Moreover, while employing simpler methods can vastly ease the application of the YFS design approach, some care should be exercised when performing the final validation. Where a structure can be well approximated by an ESDOF (e.g., symmetric, first-mode dominated without torsional issues) the rapid convergence of the YFS approach can be taken as indicative of compliance with the stated POs. However, for more complex and irregular structures, for which the ESDOF system provides only a rough and over-simplified approximation of their seismic response, a careful performance assessment of the final design via multiple nonlinear dynamic analyses can offer reliable verification of compliance. 


\section{CONCLUSIONS}

An 8-story, RC moment-resisting space frame system was designed on the basis of the Eurocodes and the recently introduced Yield Frequency Spectra framework in order to investigate their relative effectiveness and robustness for delivering structures of the desired performance. The code-based design of the building was found to be unsuccessful in terms of satisfying the code-implied performance objectives. Specifically, when the pertinent probability of exceedance was accurately checked at the level of the output response, rather than the inaccurate proxy of the input intensity, it was found to be significantly higher than the code-imposed limit and thus unsafe. Obviously, this is a result that should not be generalized beyond this case study. Different combinations of structural systems, fundamental periods, higher modes influence, site hazard etc. can easily lead to the exact opposite result, that of a conservative and highly safe design. In other words, the issue identified here with the code approach is not that it is necessarily unsafe but rather inconsistent. The blanket injection of conservativeness, mainly via the values chosen for the behavior or reduction factor, leaves a generous margin of uncertainty (a "grey zone"), where some part of the building population will be unsafe, failing to fulfil the stated performance objectives, and another part will turn out to be highly conservative and, hence, uneconomical. Simply increasing the conservativeness by further turning the same knob will decrease the unsafe cases but probably also disproportionally increase the grossly overdesigned ones. On the other hand, the YFS redesign of the building reliably led to a stiffer and stronger structure that accurately satisfied the stated objectives within a single iteration. Although nonlinear static and dynamic analyses were employed to ensure accuracy, much simpler approaches can also be used to achieve practicability. The introduction of commensurate epistemic uncertainty and the requirement of specific levels of confidence in the results, ensure that a building and performance objective specific safety factor is included, turning out designs of uniform reliability. Moreover, YFS can accommodate any number of performance objectives, offering a simple direct path both for designers and researchers to apply true Performance-Based Seismic Design.

\section{ACKNOWLEDGEMENTS}

Financial support was provided by Greece and the European Union (European Social Funds) through the Operational Program "Human Resources Development" of the National Strategic Framework (NSRF) 2007-2013, and by the European Research Executive Agency via Marie Curie grant PCIG09-GA-2011-293855. The first author was funded by the People Programme (Marie Curie Actions) of the European Union's Seventh Framework Programme (FP7/20072013) under REA grant agreement no. 609405 (COFUNDPostdocDTU). The comments provided by Professors M.A. Aschheim and E. Hernández-Montes and the contribution of Mrs Eleni Batsiou, Mr Kyriakos Mavropoulos and Mr Periklis Tassis, who assisted with the structural design software, are gratefully acknowledged.

\section{REFERENCES}

1. Structural Engineers Association of California (SEAOC). Vision 2000: A Framework for Performance-based Design, vols. I-III. Structural Engineers Association of California, Sacramento, 1995.

2. Federal Emergency Management Agency (FEMA). NEHRP guidelines for the seismic rehabilitation of buildings. Report No. FEMA-273, Washington, DC, 1997.

3. Federal Emergency Management Agency (FEMA). NEHRP recommended provisions for seismic 
regulations for new buildings and other structures. Report No. FEMA-302, Washington, DC, 1997.

4. American Society of Civil Engineers (ASCE). Minimum design loads for buildings and other structures. Report No. ASCE/SEI 07/10, Reston, Virginia, 2013.

5. Cornell CA, Krawinkler H. Progress and challenges in seismic performance assessment. PEER Center News 2000; 3 (2), URL http://peer.berkeley.edu/news/2000spring/index.html, [May 2013].

6. Krawinkler H, Zareian F, Medina RA, Ibarra LF. Decision support for conceptual performancebased design. Earthquake Engineering and Structural Dynamics 2006; 35(1):115-133. DOI: 10.1002/eqe.536.

7. Mackie KR, Stojadinovic B. Performance-based seismic bridge design for damage and loss limit states. Earthquake Engineering and Structural Dynamics 2007; 36(13):1953-1971. DOI: 10.1002/eqe.699.

8. Fragiadakis M, Papadrakakis M. Performance-based optimum seismic design of reinforced concrete structures. Earthquake Engineering and Structural Dynamics 2008; 37(6):825-844. DOI: 10.1002/eqe.786.

9. Franchin P, Pinto P. Method for probabilistic displacement-based design of RC structures. Journal of Structural Engineering 2012; 138 (5): 585-591. DOI: 10.1061/(ASCE)ST.1943-541X.0000492.

10. Lazar N, Dolsek M. Risk-based seismic design - An alternative to current standards for earthquake-resistant design of buildings. Proceedings of the 15th World Conference on Earthquake Engineering, Lisbon, Portugal, 2012.

11. Moehle JP. Displacement-based design of RC structures subject to earthquakes. Earthquake Spectra 1992; 8(3):403-428. DOI: 10.1193/1.1585688.

12. Calvi GM, Kingsley GR. Displacement-based seismic design of multi-degree-of-freedom bridge structures. Earthquake Engineering and Structural Dynamics 1995; 24(9):1247-1266. DOI: 10.1002/eqe.4290240906.

13. Priestley MJN. Performance based seismic design. Bulletin of the New Zealand Society for Earthquake Engineering 2000; 33(3):325-346.

14. Panagiotakos TB, Fardis MN. A displacement-based seismic design procedure for RC buildings and comparison with EC8. Earthquake Engineering and Structural Dynamics 2001; 30(10):14391462. DOI: $10.1002 /$ eqe.71.

15. Aschheim M. Seismic design based on the yield displacement. Earthquake Spectra 2002; 18(4): 581-600. DOI: 10.1193/1.1516754.

16. Vamvatsikos D, Kazantzi AK, Aschheim MA. Performance-based seismic design: Avant-garde and code-compatible approaches. ASCE-ASME Journal of Risk and Uncertainty in Engineering Systems, Part A: Civil Engineering 2016, 2(2): C4015008. DOI: 10.1061/AJRUA6.0000853.

17. Vamvatsikos D, Aschheim M. Performance-based seismic design via yield frequency spectra. Earthquake Engineering and Structural Dynamics 2016; 45(11):1759-1778.

18. Vamvatsikos D, Cornell CA. Applied incremental dynamic analysis. Earthquake Spectra 2004; 20(2):523- 553. DOI: 10.1193/1.1737737.

19. Cornell CA, Jalayer F, Hamburger RO, Foutch DA. The probabilistic basis for the 2000 SAC/FEMA steel moment frame guidelines. Journal of Structural Engineering 2002; 128(4):526533. DOI: 10.1061/(ASCE)0733-9445(2002)128:4(526).

20. Haselton CB. Assessing seismic collapse safety of modern reinforced concrete moment frame buildings. PhD Thesis, Stanford University, CA, US.

21. CEN. European Standard EN 1990. Eurocode: Basis of structural design. European Committee for 
Standardization, Brussels, Belgium, 2002.

22. CEN. European Standard EN 1992-1. Eurocode 2: Design of concrete structures. Part 1: General rules and rules for buildings. European Committee for Standardization, Brussels, Belgium, 2002.

23. CEN. European Standard EN 1998-1. Eurocode 8: Design of structures for earthquake resistance. Part 1: General rules, seismic actions and rules for buildings. European Committee for Standardization, Brussels, Belgium, 2004.

24. Institution of Structural Engineers (ISE). Manual for the seismic design of steel and concrete buildings to Eurocode 8. IStructE Ltd, London, UK, 2010. ISBN: 9781906335069.

25. Avramidis I, Athanatopoulou A, Morfidis K, Sextos A, Giaralis A. Eurocode-Compliant Seismic Analysis and Design of R/C Buildings. Springer International Publishing, 2016. eBook ISBN: 9783-319-25270-4.

26. Vamvatsikos D, Cornell CA. Incremental dynamic analysis. Earthquake Engineering and Structural Dynamics 2002; 31(3):491-514. DOI: 10.1002/eqe.141.

27. Mazzoni S, McKenna F, Scott M, Fenves G. Open system for earthquake engineering simulation: OpenSees command language manual. University of California, Berkeley, CA. 2000 (Accessed online http://opensees.berkeley.edu, April 2014).

28. Popovics S. A numerical approach to the complete stress strain curve for concrete. Cement and Concrete Research 1973; 3(5):583-559. DOI: 10.1016/0008-8846(73)90096-3.

29. Mander JB, Priestley MJN, Park R. Theoretical stress-strain model for confined concrete. Journal of Structural Engineering 1988; 114(8):1804-1826. DOI: 10.1061/(ASCE)0733-9445(1988) 114:8(1804).

30. Federal Emergency Management Agency (FEMA). Seismic Performance Assessmment of Buildings - Volume 1 Methodology. FEMA-P-58-1, Washington, DC, 2012

31. Eads L, Miranda E, Krawinkler H, Lignos DG. An efficient method for estimating the collapse risk of structures in seismic regions. Earthquake Engineering \& Structural Dynamics 2013; 42(1):25-41. DOI: 10.1002/eqe.2191.

32. Chiou B, Darragh R, Gregor N, Silva W. NGA Project strong-motion database. Earthquake Spectra 2008; 24 (1): 23-44. DOI: 10.1193/1.2894831.

33. Katsanos EI, Sextos AG. Inelastic spectra to predict period elongation of structures under earthquake loading. Earthquake Engineering and Structural Dynamics 2015; 44(11):1765-1782. DOI:10.1002/eqe.2554.

34. Vamvatsikos D, Cornell CA. Developing efficient scalar and vector intensity measures for IDA capacity estimation by incorporating elastic spectral shape information. Earthquake Engineering and Structural Dynamics 2005; 34(13):1573-1600. DOI: 10.1002/eqe.496.

35. Luco N, Bazzurro P. Does amplitude scaling of ground motion records result in biased nonlinear structural drift responses? Earthquake Engineering and Structural Dynamics 2007; 36 (13): 18131835. DOI: 10.1002/eqe.695.

36. Dimopoulos AI, Bazeos N, Beskos DE. Seismic yield displacements of plane moment resisting and x-braced steel frames. Soil Dynamics and Earthquake Engineering 2012; 41:128-140. DOI: 10.1016/j.soildyn.2012.05.002.

37. Federal Emergency Management Agency (FEMA). Improvement of Nonlinear Static Seismic Analysis Procedures. Report No. FEMA-440, Washington, DC, 2005.

38. Miranda E. Approximate lateral deformation demands in multistory buildings. Journal of Structural Engineering 1999; 125 (4): 417-425. DOI: 10.1061/(ASCE)0733-9445(1999) 125:4(417). 
39. Gupta A, Krawinkler K. Estimation of seismic drift demands for frame structures. Earthquake Engineering and Structural Dynamics 2003; 29 (9): 1287-1305. DOI: 10.1002/1096-9845 (200009)29:9<1287::AID-EQE971>3.0.CO;2-B.

40. Xue Q, Wu C-W. Preliminary detailing for displacement-based seismic design of buildings. Engineering Structures 2006; 28 (3): 431-440. DOI: 10.1016/j.engstruct.2005.08.015.

41. Aschheim, M, Maurer E, Browning JP. Dependency of COD on ground motion intensity and stiffness distribution. Structural Engineering and Mechanics 2007; 27 (4): 425-438.

42. Vamvatsikos D., M. Aschheim. YFSapp: Yield Frequency Spectra application tool. URL http://users.ntua.gr/divamva/software/YFSapp.xls [accessed 23/Sep/2015].

43. Priestley MJN, Calvi GM, Kowalsky MJ. Displacement Based Seismic Design of Structures. IUSS Press 2007, Pavia. Italy.

44. Tjhina NT, Aschheim M, Wallace J. Yield displacement-based seismic design of RC wall buildings. Engineering Structures 2007; 29 (11): 2946-2959. DOI: 10.1016/j.engstruct. 2006.10.022

45. Priestley MJN, Calvi GM. Concepts and procedures for direct-displacement based design and assessment. In: Seismic Design Methodologies for the Next Generation of Codes, Fajfar P, Krawinkler H (eds). A.A. Balkema, Rotterdam, the Netherlands, 1997.

46. Asimakopoulos AV, Karabalis DL, Beskos DE. Estimation of yield displacement profiles in displacement-based seismic design of steel moment resisting frames. Report No 03/2006, Department of Civil Engineering, University of Patras, Patras, Greece, 2006. 